\title{
Airborne surface temperature differences of the different Local Climate Zones in the urban area of a medium sized city
}

\author{
Skarbit N, Gál T, Unger J \\ Department of Climatology and Landscape Ecology \\ University of Szeged \\ Szeged, Hungary \\ skarbitn@geo.u-szeged.hu
}

\begin{abstract}
This paper presents a case study about the surface temperature characteristics of the different Local Climate Zones (LCZ) in Szeged, Hungary. For the evaluation we apply high resolution surface temperature data acquired by a low-cost small-format digital imaging system, measured in early night hours. The map of Local Climate Zones for the study area is derived by an automatic GIS method for LCZ classification. The results show that the different $L C Z$ classes have different surface temperature characteristics. Among the densely populated LCZ classes the open low-rise has the lowest surface temperature, thus it is can be the most favorable urban built-up type if the aim is the decrease the effect of the urban heat load.
\end{abstract}

\section{INTRODUCTION}

The Local Climate Zone (LCZ) classification system presented by Stewart and Oke [1] is an outstanding method to represent the local thermal climate. Nowadays this system in used world-wide to describe urban measurement sites, separate different parts of cities or applied as a parameterization for climate models. This system is connected with the near surface air temperature $\left(\mathrm{T}_{\mathrm{a}}\right)$, which has close connection with surface temperature $\left(T_{\mathrm{s}}\right)$ [2]. The difference of the air temperature in each LCZ is obvious [3]. It is still an open question whether the characteristics of surface temperature differ as significantly as the air temperature in different LCZ types. To answer this question the aim of this paper is to examine of the early night-time surface temperature data sets in Szeged, Hungary [2] by LCZ types, and to analyze its alteration between different classes. We investigated the thermal characteristics of the whole area (using the whole measured data) and separately, only of the ground area.

\section{SURFACE TEMPERATURE}

\section{A. Study area}

Szeged is located in the south-eastern part of Hungary $\left(46^{\circ} \mathrm{N}, 20^{\circ} \mathrm{E}\right)$ at $79 \mathrm{~m}$ above sea level on a flat plain (Fig. 1). It belongs to the climatic region $C f$ according to Köppen's classification (temperate warm climate with uniform annual distribution of precipitation) [2]. Szeged provides a favorable background for urban climate research, since its climate is free from the influences of orography and large water bodies.

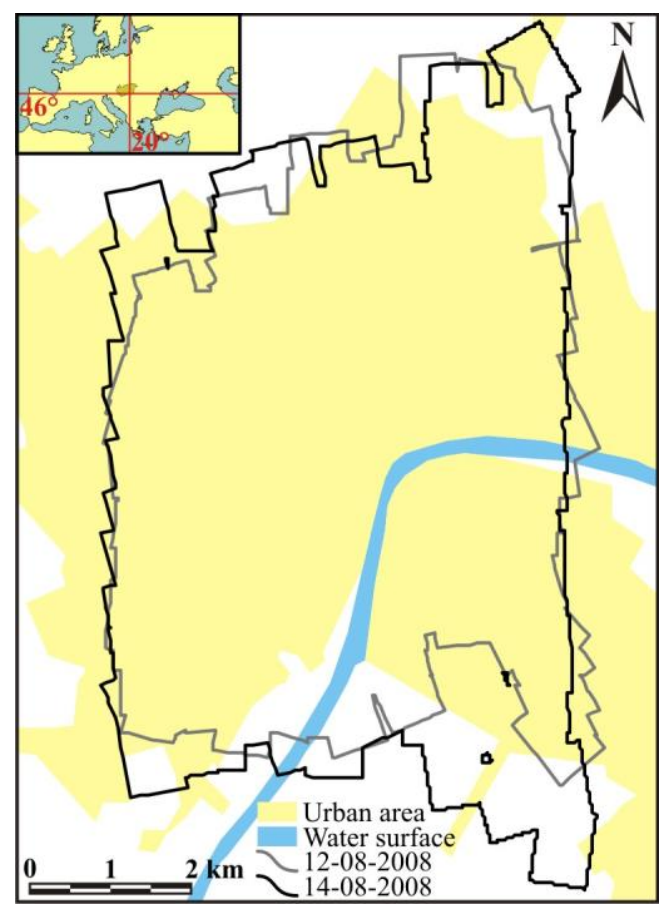

Fig. 1. Location of the study area and the boundary of the obtained thermal mosaics on the measurement days

The city's population of about 160000 lives within an administration district of $281 \mathrm{~km}^{2}$, but the highly urbanized area is restricted to an area of about $30-35 \mathrm{~km}^{2}$. In the course of the $19^{\text {th }}$ century, a structure of boulevards and avenues was established using the river Tisza as an axis.

\section{B. Weather situation}

The observed $T_{a}$ and $T_{s}$ values depend not only on the momentary weather conditions but on the conditions prevailing in the previous time period as well. In this case the 36-hour periods preceding the measurements on 12 and 14 August 2008 were taken into account (altogether 86 hours).

According to the data of the meteorological station at the University operated by the Hungarian Meteorological Service, the insolation was undisturbed during the daylight hours with 
maximum values of $810-860 \mathrm{Wm}^{-2}$. On the whole 86 -hour period, the air movement was moderate (0-4.7 $\left.\mathrm{ms}^{-1}\right)$ and during the measurements it ranged between 0.8 and $3.1 \mathrm{~ms}^{-1}$. The days were rather warm with maximum values of $28-36^{\circ} \mathrm{C}$ and with minimum values of $17-22^{\circ} \mathrm{C}$ at dawn. Consequently, during the investigated period the weather conditions promoted the microclimatic effects of the surface features in Szeged.

\section{Surface temperature measurements}

The thermal measurements were carried out using a selfdeveloped low-cost small-format digital imaging system. The current system is based on the experiences gained during earlier research using thermal [4] and CIR (Color-InfraRed) Small Format Aerial Photography (SFAP) data collected with a small airplane [5]. The system is based on a FLIR ThermaCam P65 thermal camera integrated with a navigation system and a GPS/GNSS receiver (Mobile Mapper CE) [6]. The FLIR (forward looking infrared radiometer) is a compact single-band thermal camera with a temperature sensitivity of $0.08^{\circ} \mathrm{C}$. The instrument can measure temperatures between $40^{\circ} \mathrm{C}$ and $+500^{\circ} \mathrm{C}$ and has a resolution of $320 \times 240$ pixels. The camera has germanium lenses to register the thermal radiation emitted by the object of investigation.

The flight was planned to achieve $2.5 \mathrm{~m}$ resolution with standard photogrammetry overlapping, thus the speed was 120 $\mathrm{km} \mathrm{h}^{-1}$ and the height was $2000 \mathrm{~m}$ agl. The progress in the flight plan was controlled and recorded with Mobile Mapper CE GPS/GNSS receiver.

The measurements in August took place around sunset because there was less direct shortwave radiation disturbing the signals recorded by the camera at that time and the flight did not violate the flight ban of after 22.00 LST. As sunset was at 19.57 LST (17.57 UTC), the airborne images were taken between 18.15 and 19.45 UTC [2].

After the survey, the acquired data needed to be postprocessed. Using software specifically designed for the analysis of the thermal images, several parameters needed to be readjusted. Using the results of the parallel fieldwork the data was calibrated with measured surface temperatures [2].

As a next step the coordinates of the center points of each separated image was extracted from the GPS track log. These coordinates and the resolution combined to a simple text file (world file). It was the basis of the preliminary coarse geometric correction. These coarse georeferenced images were combined to one single thermal mosaic image by days with a resolution $2.5 \mathrm{~m} \mathrm{[2]} \mathrm{(Fig.} \mathrm{1).}$

It was assumed that some decrease can be found in the surface temperatures during the flight times (50 and 51 minutes in 12 and 14 August, respectively). If this dependence from the time is significant, the pixel values have to be corrected to the middle time (19.00 UTC) of the survey according to the general cooling tendency. A statistically established trend was found only in the evening of 14 August [2].
TABLE I. NAMES AND CODES OF THE LCZ TYPES (AFTER [1])

\begin{tabular}{|c|c|c|c|}
\hline \multicolumn{2}{|c|}{ Built types } & \multicolumn{2}{c|}{ Land cover types } \\
\hline LCZ 1 & compact high-rise & LCZ A & dense trees \\
\hline LCZ 2 & compact mid-rise & LCZ B & scattered trees \\
\hline LCZ 3 & compact low-rise & LCZ C & bush, scrub \\
\hline LCZ 4 & open high-rise & LCZ D & low plants \\
\hline LCZ 5 & open mid-rise & LCZ E & bare rock / paved \\
\hline LCZ 6 & open low-rise & LCZ F & bare soil / sand \\
\hline LCZ 7 & lightweight low-rise & LCZ G & water \\
\hline LCZ 8 & large low-rise & & \\
\hline LCZ 9 & sparsely built & & \\
\hline LCZ 10 & heavy industry & & \\
\hline
\end{tabular}

\section{LOCAl Climate ZONES IN SZEGED}

\section{A. Classification of the Local Climate Zones}

The original purpose of the LCZ system was the characterization of the local environment around a temperature measurement site in terms of its ability to influence the local air thermal climate. Therefore, the number of types is not too large and their separation is based on objective, measurable parameters. LCZs are defined as "regions of uniform surface cover, structure, material, and human activity that span hundreds of meters to several kilometers in horizontal scale" [1]. Their names reflect the main characteristics of the types (Table 1).

The LCZ types can be distinguished by typical value ranges of measurable physical properties. These properties describe the surface geometry and cover (sky view factor, aspect ratio, fractions of building, pervious and impervious surfaces, height of roughness elements, terrain roughness class) as well as the thermal, radiative and anthropogenic energy (surface admittance and albedo, anthropogenic heat output) features of the surface. As a result, the LCZ system consists of ten 'built' and seven 'land cover' LCZ types (Table 1). Although the system was not originally designed for mapping, the mapping of the urban terrain can be proved an efficient use of the system to determine areas which are relatively homogeneous in surface properties and human activities.

In the context of the LCZ classification system, the urban heat island intensity is not an 'urban-rural' near surface air temperature difference $\left(\Delta \mathrm{T}_{\mathrm{u}-\mathrm{r}}\right)$, but an air temperature difference between pairs of $L C Z$ types $\left(\Delta T_{L C Z ~ X-Y}\right)$, that is an inter-zone temperature difference [3]. Consequently, the usage of the system allows the objective comparison of the thermal reactions in different areas within a city and between cities (intra-urban and inter-urban comparisons).

\section{B. Spatial pattern of the Local Climate Zones in Szeged}

In order to apply the LCZ system in the study area, that is to delineate the types occurring therein, a recently developed automated method was used [7]. Altogether seven 'built' and five 'land cover' LCZ types were obtained. Their pattern in and around Szeged is presented partly in Fig. 2. 


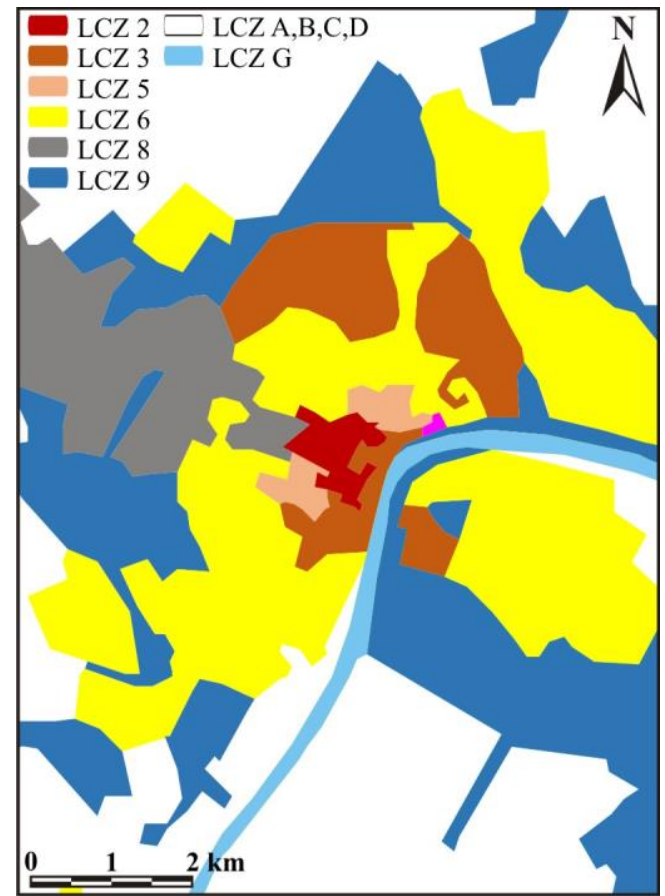

Fig. 2. LCZ map of the study area in Szeged focusing on the built type LCZs (see Table 1 too)

\section{SURFACE TEMPERATURE CHARACTERISTICS OF LCZS}

To obtain the surface temperature characteristics of the different LCZs each surface temperature reading was overlaid with the LCZ polygons. In order to examine the characteristics of the ground area the thermal mosaic was also overlaid with building footprints of Szeged. Finally each measured surface temperature value stored into a text file with its LCZ type (2, $3,5,6,8,9$ and 0 for land cover types (A, B, C, D, G)) and with building identifier ( 1 for building and 0 for ground). From this text file the basic statistical parameters of different LCZs were calculated with Fortran algorithms.

\section{A. Surface temperature in the total area}

Fig. 3a presents the frequency of surface temperature by LCZ classes on $12^{\text {th }}$ August for the total surface. The most frequent temperatures range between 21 and $25^{\circ} \mathrm{C}$. Compared to the other types the $\mathrm{T}_{\mathrm{s}}$ of LCZ 9 is different, because it has no specific range with large frequencies. For the aggregated land cover zones there are two $\mathrm{T}_{\mathrm{s}}$ peaks: the smaller is at $15^{\circ} \mathrm{C}$, while the larger is at $21{ }^{\circ} \mathrm{C}$ and the range is slightly similar to LCZ 9. The high temperature values appear more often in cases of LCZ 8 and LCZ 2.

The frequency of the surface temperature for LCZ types on $14^{\text {th }}$ August is slightly different (Fig. 3b). The reason for the larger frequency of higher values is the continuous warming tendency of the weather situation during these days. The majority of LCZs the temperature range between 27 and $29^{\circ} \mathrm{C}$ are the most common. In this case the LCZ 9 is also different, where this range is between 23 and $25^{\circ} \mathrm{C}$. In case of land cover zones there is only one $\mathrm{T}_{\mathrm{s}}$ peak with high frequency around $24^{\circ} \mathrm{C}$.
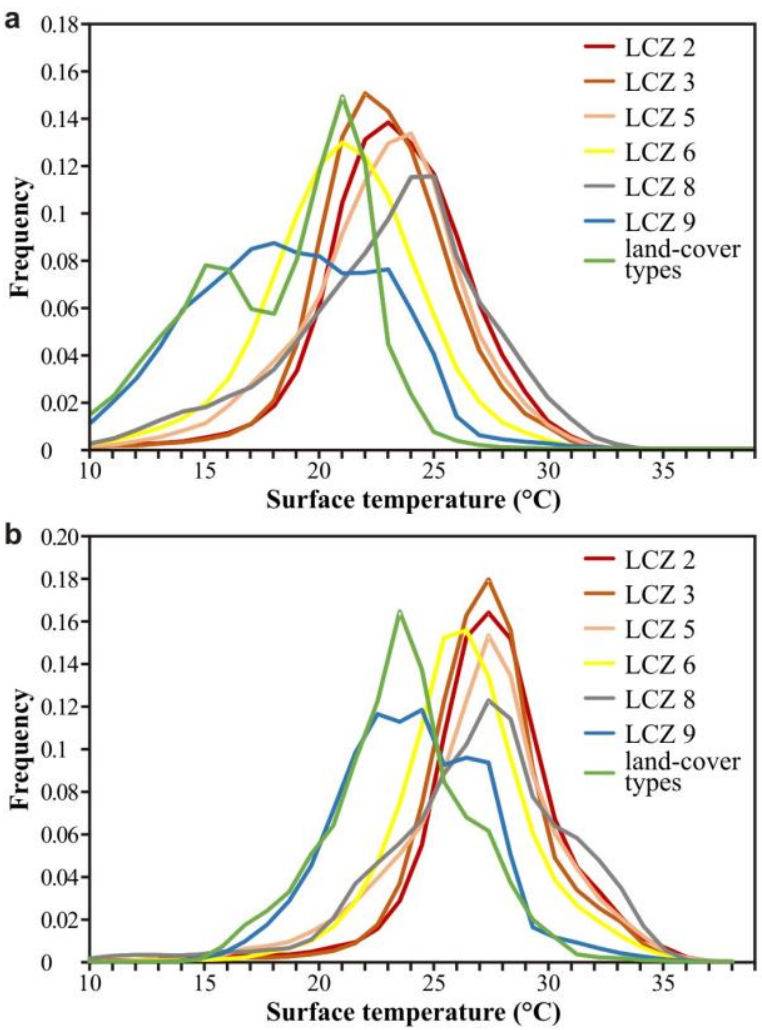

Fig. 3. Frequencies of the surface tempereature on $12^{\text {th }}$ August (a) and $14^{\text {th }}$ August (b) 2008 for the total surface area
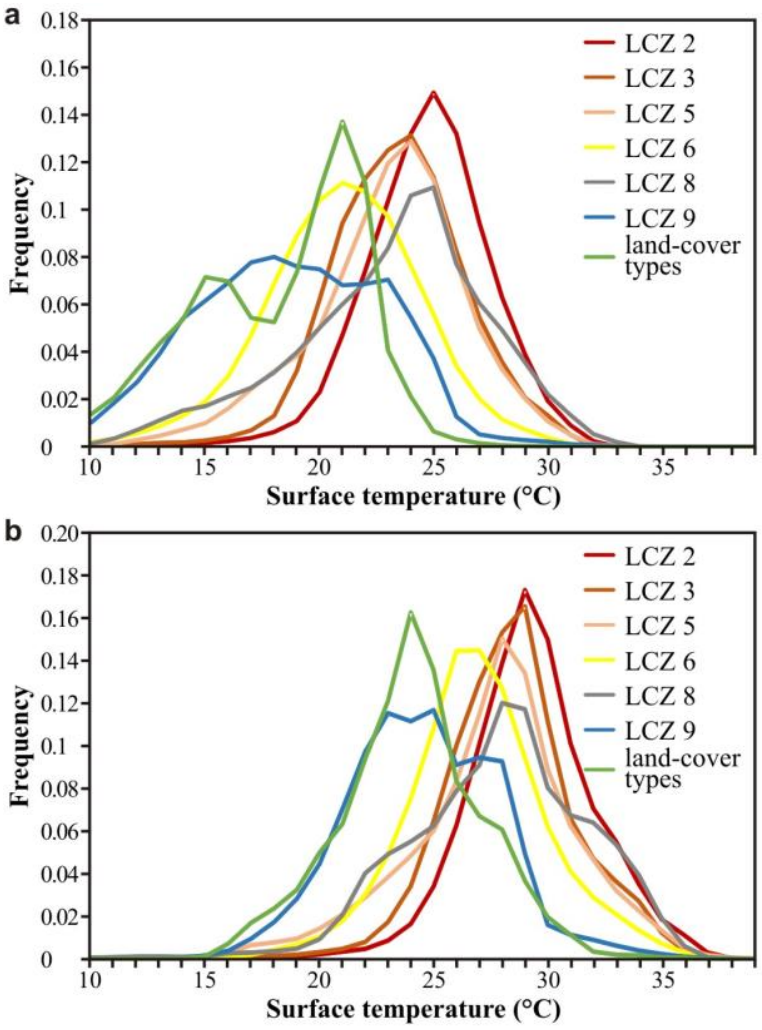

Fig. 4. Frequencies of the surface tempereature on $12^{\text {th }}$ August (a) and $14^{\text {th }}$ August (b) 2008 for only the ground area 


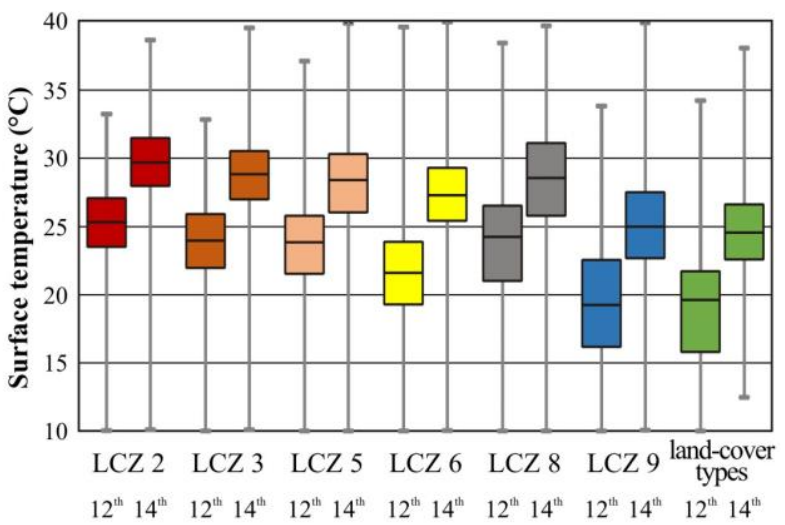

Fig. 5. Box-plot diagram of the surface tempereature on $12^{\text {th }}$ August and $14^{\text {th }}$ August 2008 for only the ground area

\section{B. Ground temperatures}

The frequency pattern of the surface temperature values for only the ground surface on $12^{\text {th }}$ August is a bit similar to the total surface, but few significant differences are present (Fig. 4a). The highest values have a wider range compared to the total area. The shape of $T_{s}$ distribution in LCZ 9 is similar to the total surface area (Fig. 3a). For the land cover zones and LCZ 6 the value of $21^{\circ} \mathrm{C}$ is the most common, but the distribution is different: the double $\mathrm{T}_{\mathrm{s}}$ peak also appear in the land cover zones. LCZs 3 and 5 are similar and the most frequent values are between 23 and $25^{\circ} \mathrm{C}$. The other two similar LCZs are 8 and 2 with the peak at $25^{\circ} \mathrm{C}$.

The most frequent temperatures on $14^{\text {th }}$ August are also shifted compared to the other investigated day (Fig. 4b). The distribution is similar to the total surface case (Fig. 3b), but there are only minor differences. For example in cases of LCZ 2 and 3 the most frequent values are higher and are around $29^{\circ} \mathrm{C}$.

The box-plot diagrams allow further findings about the $\mathrm{T}_{\mathrm{s}}$ characteristics of LCZs (Fig. 5.). The LCZ 2 differs from the others both days as the median temperatures $\left(\sim 26^{\circ} \mathrm{C}\right.$ and $\sim 29^{\circ} \mathrm{C}$ ) and also the upper and lower hinges are the highest. The LCZ 3 is mostly similar to LCZ 5, but its lower hinge is closer to the median. The LCZ 6 separated form first three most urbanized type, its temperature range is not so high. LCZ 8 has wide temperature range as its upper hinge and median are close to LCZ 2 but the lower hinge is close to LCZ 6. The LCZ 9 is mostly similar to the land cover types but its upper $\mathrm{T}_{\mathrm{s}}$ hinge is significantly higher than the one of the aggregated non-urbanized LCZ types.

\section{CONCLUSIONS}

As a conclusion we can state that the obtained surface temperature are differs in the different Local Climate Zones in the studied urban area. The difference is less significant than in the case of air temperature in some LCZs (e.g. compact mid-rise, compact low-rise and open mid-rise). Based on the results the open low-rise type (LCZ 6) has the lowest early night-time $\mathrm{T}_{\mathrm{s}}$ within the most densely populated LCZ types. Thus, to decrease the thermal load in urban areas then the preference of this built type LCZ type can be a solution for the urban residents.

These findings are just a result of a case study and we used only the early night-time surface temperatures. Nevertheless, if there is available a detailed surface temperature data set with high temporal resolution, then more useful information can be obtained in order to help the climate mitigation strategies in the urban areas.

\section{Acknowledgment}

The study was supported by the Hungarian Scientific Research Fund (OTKA PD-100352 and K-111768) and in case of the second author by the János Bolyai Research Scholarship of the Hungarian Academy of Sciences.

\section{References}

[1] I.D. Stewart, and T.R. Oke, "Local Climate Zones for urban temperature studies," Bull. Am. Meteorol. Soc., vol. 93, 2012, pp. 1879-1900.

[2] J. Unger, T. Gál, J. Rakonczai, L. Mucsi, J. Szatmári, Z. Tobak, B. van Leeuwen, and K. Fiala, "Modeling of the urban heat island pattern based on the relationship between surface and air temperatures," Időjárás (Quarterly J. of Hungarian Meteorological Service), vol. 114, 2010, pp. 287-302.

[3] I.D. Stewart, T.R. Oke TR, and E.S. Krayenhoff, "Evaluation of the 'local climate zone' scheme using temperature observations and model simulations," Int. J. Climatol., vol. 34, 2014, pp. 1062-1080.

[4] L. Mucsi, R. Kiss, J. Szatmári, K. Bódis, Z. Kántor, G. Dabis, and M. Dzsupin, "The analysis of contamination deriving from the leakage of subsurface pipeline networks via remote sensing (in Hungarian)," Geodézia és Kartográfia, vol. 56/4, 2004, pp. 3-8.

[5] J. Szatmári, Z. Tobak, B. van Leeuwen, A. Olasz, and J. Dolleschall, "An effective and low-cost method to detect environmental contaminations: the promise of CIR small format aerial photography," 12th Geomathematics Conf., Mórahalom, Hungary, 2008

[6] J. Rakonczai, Sz. Csató, L. Mucsi, F. Kovács, and J. Szatmári, "Experiences on the evaluation of the 1999 and 2000 excess waters (in Hungarian)," Vízügyi Közlemények Különszám IV, 2003, pp. 317-336.

[7] E. Lelovics, J. Unger, T. Gál, and C.V. Gál, "Design of an urban monitoring network based on Local Climate Zone mapping and temperature pattern modelling," Clim. Res., vol. 60, 2014, pp. 5162. 